\title{
Development of Teaching Materials to Learn the Efficient Use of Energy
}

\author{
Yoshihiro Ohnishi* \\ Faculty of Education, Ehime University, 3, Bunkyocho \\ Matsuyama, Ehime 790-8577,JAPAN \\ E-mail: ohnishi@ehime-u.ac.jp \\ www. ehime-u.ac.jp \\ Teruyuki Tamai \\ E-mail: tamai.teruyuki.xq@ehime-u.ac.jp \\ Shinnosuke Mori* \\ E-mail: mori.shinnosuke.my@ehime-u.ac.jp \\ Kawada Kazuo** \\ Faculty of Education, Hiroshima University, 1-1-1, Kagamiyama \\ Higashihiroshima, Hiroshima 739-8524,JAPAN \\ E-mail:kawada@hiroshima-u.ac.jp
}

\begin{abstract}
Control technology using the computer is one of the key technologies for improving energy efficiency. PWM control, which is a control technology for DC motors, is widely used as the basis of power electronics with the development of semiconductor devices. On the other hand, programming techniques are required to effectively use these techniques. In this paper, we propose teaching materials that can visualize the performance improvement by programming as the operating time performance index of the wind turbine.
\end{abstract}

Keywords: teaching materials, electric double layer capacitor, power electronics, control engineering

\section{Introduction}

Computer-based control technology is one of the key technologies for improving energy efficiency. PWM control, which is a control technology for DC motors, is widely used as the basis of power electronics with the development of semiconductor devices. On the other hand, programming techniques are required to make effective use of these techniques. Control performance assessment[1],[2] which is a measure of how effectively control technology is working. This method originated in Harris's research[3] and is widely used in the field of process control. The authors of this paper are conducting research to apply this control performance assessment method to the achievement evaluation of programming learning[4],[5].
Since the original control performance assessment is a method based on the variance of control error, it is difficult for elementary and junior high school students to understand its meaning. Therefore, presenting more easy-to-understand index to students as a scale may lead to independent learning.

In this paper, we propose to use the operating time of the wind turbine as a performance index. Using an electric double layer capacitor (EDLC), which is used as a new storage device for electrical energy, as a power source, we provide activities to think about how to use that energy efficiently. Teaching materials that can visualize performance improvement by programming are explained. 


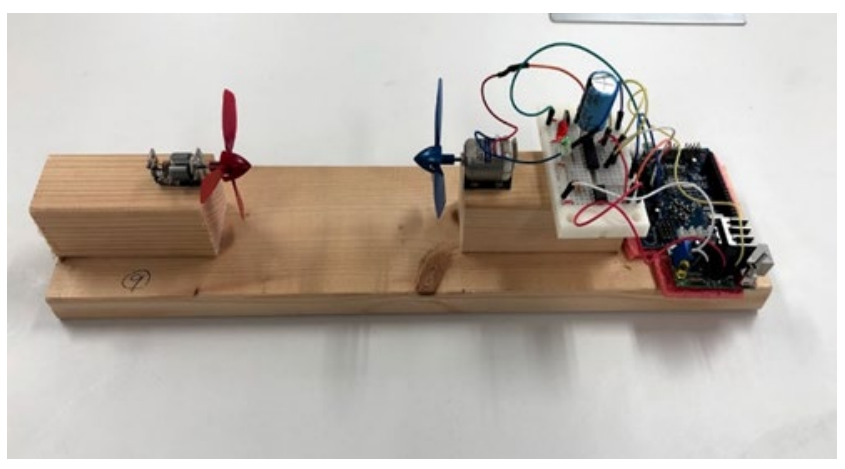

Fig. 1. The Overview of the developed equipment

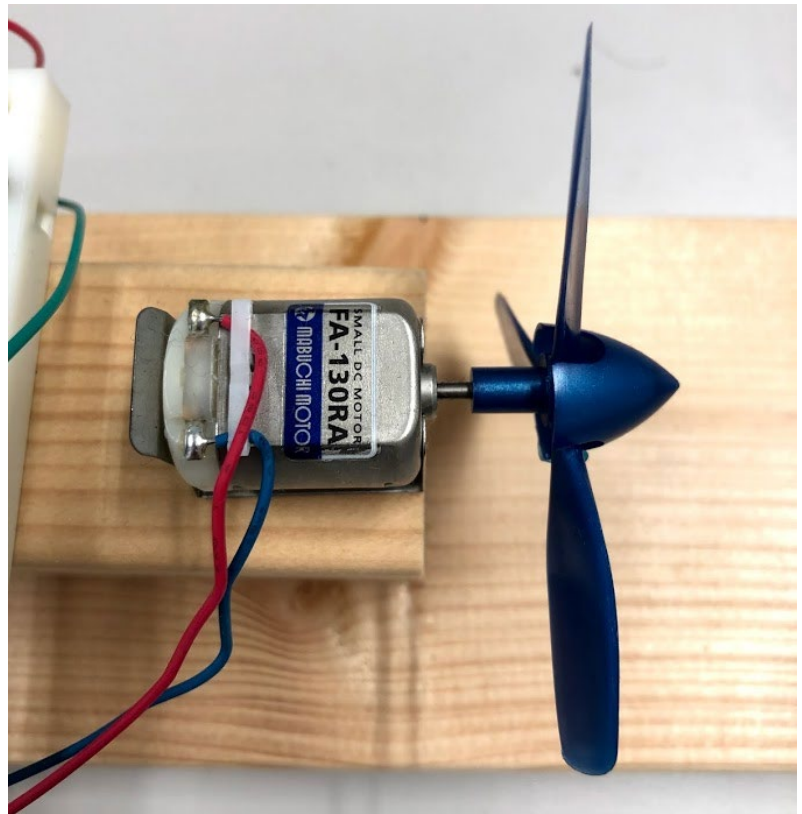

Fig. 2. The Drive wind turbine which is driven by FA-130RA.

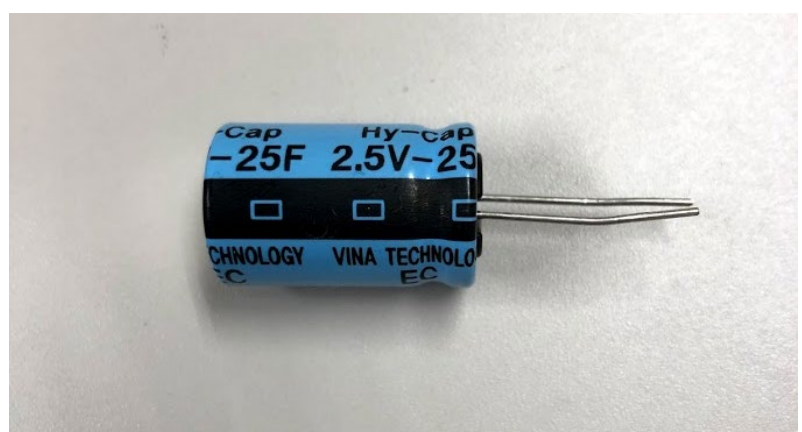

Fig. 3. Power supply Electric Double Layer Capacitor with withstand voltage $2.5 \mathrm{~V}$ and capacitance $25 \mathrm{~F}$.

\section{The Overview of the developed equipment}

The overview of the teaching device is shown in Fig. 1. The red windmill is rotated by a blue fan. The blue fan is driven by the Mabuchi DC motor FA-130RA shown in Fig. 2. The power source for the blue fan is a charged EDLC. The EDLC used as a power source is shown in Fig. 3, with a withstand voltage of $2.5 \mathrm{~V}$ and the capacitance of $25 \mathrm{~F}$. $2.5 \mathrm{~V}$ constant voltage power supply was used to charge the capacitance. This is a kit using the variable regulator NJM2397, which is shown in Fig. 4 and can be purchased at Akizuki Denshi. If the regulator for charging is turned on, the motor will rotate with the regulator as the power source instead of the EDLC. Therefore, exclusive control as shown in Table 1 is required. A circuit using NAND was constructed to achieve this exclusive control. The blue fan can be driven by PWM control. The PMW control frequency is $10 \mathrm{~Hz}$ and is programmed so that the sum of on-time and offtime is 0.1 seconds. PWM control to the motor is realized by MOSFET 2SK4017. The circuit diagram is shown in Fig. 6. A0 in Fig. 5 is the output of the ON / OFF signal from the computer, and $\mathrm{A} 4$ is the $\mathrm{AD}$ input for monitoring the voltage of the EDLC. The voltage of the A4 channel can be monitored with $3.3 \mathrm{~V}$ as the maximum value of 100. This relationship is shown as Fig.6.

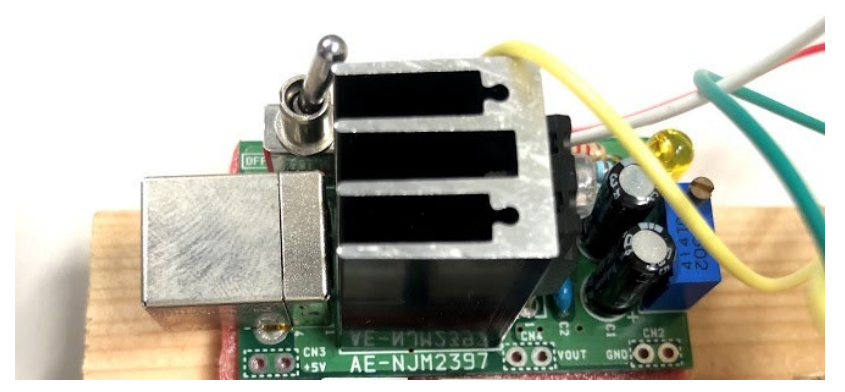

Fig. 4. Variable regulator.

Table 1. Output signal for FET.

\begin{tabular}{|c|c|c|}
\hline $\mathrm{A} 0$ & $5 \mathrm{~V}$ & Out \\
\hline 0 & 0 & 0 \\
\hline 0 & 1 & 0 \\
\hline 1 & 0 & 1 \\
\hline 1 & 1 & 0 \\
\hline
\end{tabular}




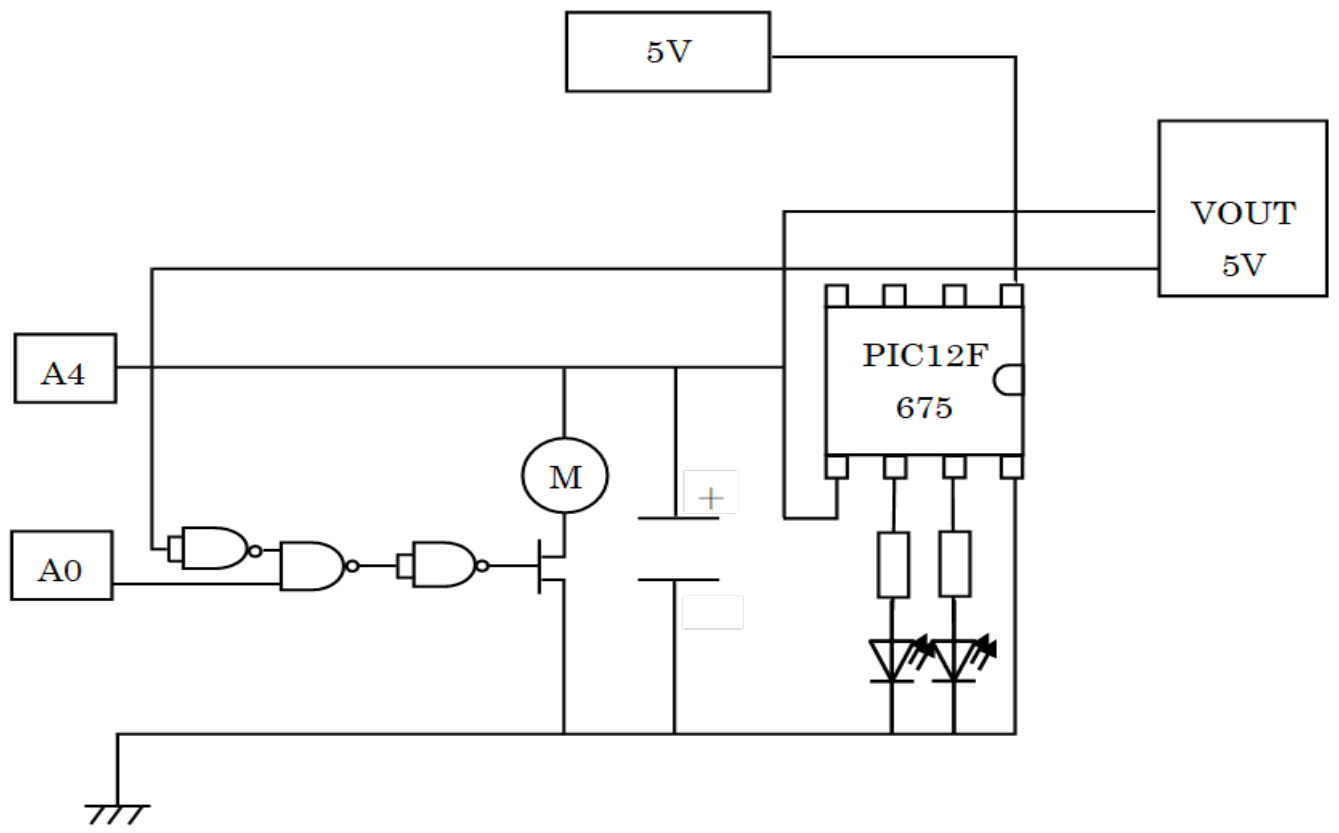

Fig. 5. Overall circuit diagram.

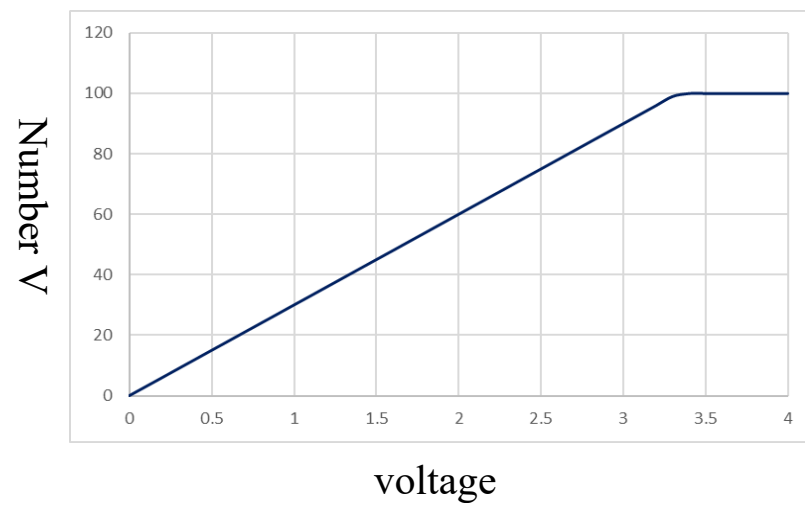

Fig. 6. The relationship between the monitoring voltage and digital number which is loaded by $\mathrm{AD}$ input.

\section{Experimental evaluation}

The purpose of the device experiment described in the previous section is to turn the red windmill as long as possible with a blue fan. At this time, the number of rotations of the red windmill does not matter, as long as it is moving. By adjusting the duty ratio of PWM control by programming, the speed of the blue fan can be changed. The control purpose is to give the minimum energy for the red windmill to move by the blue fan. Table 2 shows the results of the experiment under different conditions. First, when the duty ratio was 100\%, the time was the shortest in this experiment. Next, when the duty ratio is $50 \%$ at all times, the time is extended a little more. However, not all the energy in the EDLC can be used. Therefore, if the program is switched to a duty ratio of $50 \%$ at first and then to a duty ratio of $100 \%$ when the voltage drops, the time will be further extended. The longest time could be obtained by increasing this condition. From these results, it can be seen that the time of the result changes by changing the programming. At this time, the performance index by programming is the result time. Students try to improve programming in order to increase the time of results. Teachers can look at time and evaluate student skills.

\section{Conclusions}

In this study, we created teaching materials aimed at efficiently using the energy stored in EDLC. In order to use energy efficiently, PWM control technology is utilized, and students perform activities to increase the target performance index by programming. In actual products, energy is used efficiently by control technology such as refrigerators, air conditioners, and even hybrid vehicles. This teaching material aims to learn that. In the future, students will be able to carry out activities and their effectiveness will be verified. 
Table 2. Experimental result.

\begin{tabular}{|l|r|}
\hline Condition(Duty ratio) & Measurement time \\
\hline $\mathrm{D}=100 \%$ & $3 \mathrm{~m} 09 \mathrm{~s} 69$ \\
\hline $\mathrm{D}=50 \%$ & $3 \mathrm{~m} 31 \mathrm{~s} 99$ \\
\hline $\begin{array}{l}\text { If } \mathrm{V}>30 \text {, then } \mathrm{D}=50 \% \\
\text { else } \mathrm{D}=100 \%\end{array}$ & $36 \mathrm{~s} 83$ \\
\hline $\begin{array}{l}\text { If } \mathrm{V}>25, \text { then } \mathrm{D}=50 \% \\
\text { else } \mathrm{D}=100 \%\end{array}$ & $4 \mathrm{~m} 17 \mathrm{~s} 48$ \\
\hline $\begin{array}{l}\text { If } \mathrm{V}>65, \text { then } \mathrm{D}=20 \% \\
\text { else if } \mathrm{V}>51 \text { then } \mathrm{D}=30 \% \\
\text { else if } \mathrm{V}>37 \text { then } \mathrm{D}=50 \% \\
\text { else if } \mathrm{V}>27 \text { then } \mathrm{D}=80 \% \\
\text { else } \mathrm{D}=100 \%\end{array}$ & \\
\hline
\end{tabular}

\section{Acknowledgements}

The development of the experimental system was carried out by Mr. Tomoki Yokohama, Mr. Yuji Mukaigawa and Mr. Motoki Nanjyo former students of Ehime University. And the practical evaluation was done with kindly support by Mr. Kimitoshi Honda Junior high school teacher in Ehime prefecture. This work was supported by JSPS KAKENHI Grant Number JP18K02980.

\section{References}

1. B. Huang and S. L. Shah: Performance Assessment of Control Loops: Theory and Applications, Springer, London (1999)

2. M. Jelali: An overview of control performance assessment technology and industrial applications, Control Engineering Practice, Vol.14, pp. 441-466 (2006)

3. T. J. Harris: Assessment of Closed Loop Performance, Canadian Journal of Chemical Engineering, Vol.67, pp. 856-861 (1989)
4. Y.Ohnishi: Educational Effect Measurement of Control Technology based on Performance Index, Proceedings of the SICE Annual Conference 2019, pp. 1323-1327(2019)

5. Y.Ohnishi, T. Nakano, T. Tamai, S. Mori and K. Kawada : Practical Learning of Science for Elementary School Students via Programming and Control Experimentation, Journal of Robotics, Networking and Artificial Life, in press (2021) 